\title{
PROGRAMA BRASIL PROFISSIONALIZADO: A OFERTA DE CURSOS TÉCNICOS NA BAHIA E NO ACRE1
}

\author{
Remi Castioni
}

\begin{abstract}
Resumo
O presente texto contempla um estudo descritivo sobre a oferta de Educação Profissional nos estados do Acre e da Bahia. A eleição desses estados tomou como premissa a ideia de que esses guardam características diferenciadas de gestão da Educação Profissional, no âmbito dos órgãos estaduais. Para este estudo, tomaram-se, como elementos de análise, algumas variáveis que permitem conhecer a forma de gestão do programa Brasil Profissionalizado.
\end{abstract}

Palavras-chave: Educação Profissional. Brasil Profissionalizado. PRONATEC.

\begin{abstract}
This text presents a descriptive study about the offer of professional education in the Brazilian states of Acre and Bahia. The choice of these states took as a premise the idea that they have different characteristics of management of professional education, within the state organs. For the analysis of this study, we considered some variables that allow us to know the form of management of the program Brasil Profissionalizado.
\end{abstract}

Keywords: Professional Education. Brasil Profissionalizado. PRONATEC.

\section{Introdução}

$\mathrm{Na}$ década de 1990, diversos países latino-americanos implementaram programas voltados à formação profissional de trabalhadores e oferta de novas perspectivas aos jovens, tendo como horizonte a formação para o trabalho. Os programas mais conhecidos no Brasil foram aqueles conduzidos pelo Ministério do Trabalho e Emprego (PLANFOR e PNQ), substituídos, em 2011, por meio da Lei no 12.513/2011, pelo Programa Nacional de Acesso ao Ensino Técnico e Emprego - PRONATEC. No Chile, implementou-se o Programa Chile Joven e posteriormente, seguindo a mesma estratégia do Brasil, e quiçá inspirador do próprio Pronatec, uma vez que ele se iniciou em 2002, o Chile Califica (SANTIAGO CONSULTORES, 2009).

\footnotetext{
${ }^{1}$ DOI: https://doi.org/10.22409/tn.16i30.p10087

${ }^{2}$ Doutor em Educação (Unicamp). Professor da Faculdade de Educação, da Universidade de Brasília (UnB). Membro permanente dos Programas de Pós-Graduação em Educação (profissional e acadêmico). Contato: remi@unb.br
} 
No entanto, os índices alarmantes de desemprego juvenil verificados nas últimas décadas passaram a vincular o sucesso de políticas de enfrentamento aos problemas da juventude ao delineamento de programas voltados para a melhoria da escolaridade e relacionados à oferta de Educação Profissional. No Brasil, ganharam projeção nacional as ações do PRONATEC e a expansão da Educação Profissional integrada ao Ensino Médio, em boa medida favorecida pela expansão da Rede Federal de Educação Profissional (VERA; CASTIONI, 2010). Assim, a política de Educação Profissional passou a ser considerada como uma das prioridades do governo brasileiro, como forma de ampliar as opções de formação do trabalhador brasileiro e oportunizar o acesso de candidatos ao mundo do trabalho, com uma formação mais próxima das demandas locais.

A implementação do Programa Brasil Profissionalizado derivou de um conjunto de ações anunciadas durante 0 lançamento do Plano de Desenvolvimento da Educação - PDE, em 24 de abril de 2007. Tinha como paralelo o que se pretendia com a Rede Federal - apoiar as redes estaduais de Educação Profissional e Tecnológica -, para fazer o mesmo por meio de obras de infraestrutura, equipamentos, desenvolvimento de gestão, práticas pedagógicas e formação de professores (BRASIL, 2007).

Nesse sentido, a presente reflexão oferece um panorama da gestão do Programa Brasil Profissionalizado no âmbito dos estados da Bahia e do Acre, por terem sido dois estados que tiveram desempenho acima da média. O primeiro porque desde a primeira gestão dos governos petistas, exatamente a partir de 2007, criou um modelo de gestão própria para a Educação Profissional. O estado do Acre, também por praticamente não ter trajetória na área da Educação Profissional, beneficiou-se tanto da expansão da Rede Federal no próprio estado como da criação também de uma estrutura autônoma em relação à tradicional Secretaria de Educação, com encargos diretos sobre a Educação Profissional.

As medidas adotadas nos últimos anos, particularmente com 0 PRONATEC e a expansão da Rede Federal, conectam-se com o ambicioso marco da educação determinado pelo Plano Nacional da Educação - PNE, na forma da Lei no 13.005/2014, com vigência para os próximos dez anos. Essa lei propõe metas que afetam diretamente a oferta de Educação Profissional, entre elas a Meta 11, de triplicar as matrículas da Educação Profissional técnica de 
nível médio, com pelo menos $50 \%$ (cinquenta por cento) da expansão no segmento público (FASOLO; CASTIONI, 2017). O PRONATEC, desde 2015, sofreu com o corte de recursos e praticamente foi descontinuado.

\section{A trajetória da EPT nos estados brasileiros}

Pensar sobre a importância da Educação Profissional e Tecnológica no âmbito de atuação de dois estados brasileiros, considerando as constantes mudanças advindas com as novas tecnologias e as alterações nas leis trabalhistas, atrelada ao processo de precarização do mercado de trabalho, remete a uma discussão que perpassa, necessariamente, pelas relações entre capital e trabalho no Brasil e que tem como marca um sistema nada democrático de não reconhecer o conflito como algo presente nas relações de trabalho. Nesse particular, a própria construção social da formação profissional deixa de ser fruto do embate de contrários e passa a ser concebida como dádiva, seja ela como concessão operada pelo próprio Estado ou por ele outorgada (CASTIONI, 2010).

É fato que o surgimento da formação profissional, de modo institucionalizado, se deu por volta de 1809 , com a criação do Colégio das Fábricas. No entanto, com a fundação das Escolas de Aprendizes Artífices, de fundo assistencialista, um século depois, essa ação se fortaleceu. Contudo, foi na década de 1930 que essas instituições passaram a ter um caráter de formação de trabalhadores e vieram integrar o ordenamento jurídico nacional. A Constituição de 1937, do Estado Novo, no seu artigo 129, com o objetivo de atender às demandas do desenvolvimento econômico no início da industrialização, acabou por consagrar a dicotomia existente no ensino. Assim, a meta do ensino secundário e normal era o de "formar as elites condutoras do país", enquanto o ensino profissional tinha como objetivo oferecer "formação adequada aos filhos dos operários, aos desvalidos da sorte e aos menos afortunados, àqueles que necessitam ingressar precocemente na força de trabalho" (WEREBE, 1994, p. 57), quando o país passava de uma sociedade eminentemente agrária para uma sociedade industrial.

Fruto das demandas dessa nova organização social, a questão da formação dos trabalhadores passou a assumir espaço de relevância, tendo em 
vista a carência de profissionais qualificados para atender esse novo panorama. Posteriormente, com base nesse contexto, foi criado em 1942 o Serviço Nacional de Aprendizagem Industrial; e em 1943, o Serviço Nacional de Aprendizagem Comercial. Essa embrionária ação deu-se notadamente nos estados do Sul, de maneira especial nos núcleos urbanos de São Paulo e Rio de Janeiro.

A partir desse contexto, a relação entre escola e mundo do trabalho passou a ganhar maior relevância no âmbito acadêmico. O debate permeia toda a história da educação e instala uma dualidade entre educação secundária/média e formação profissional - formação para a vida ou formação para o trabalho.

No que diz respeito à finalidade do Ensino Médio, previsto na Lei de Diretrizes e Bases da Educação Nacional (Lei no 9.394/96), essa consiste na apropriação dos fundamentos básicos para o exercício da cidadania e para a inserção no mundo do trabalho (BRASIL, 1996). No entanto, a concretização dessa finalidade tem provocado intensos debates e confrontos, ao longo dos anos. As constantes reformas do Ensino Médio evidenciam esses embates - ora atende a um viés propedêutico, ora atende ao viés profissionalizante; e em outro dado momento, à possibilidade de articulação/integração ou não com a formação profissional (proposta vigente nos dias atuais), a partir da Lei ํㅜ 13.415/2017.

Sem querer adentrar em toda a centenária trajetória da Educação Profissional, limitação essa derivada do tema, tomaram-se como ponto de reflexão o ano de 2005, a partir das determinações do Decreto $n^{0}$ 5.154/2004, e o ano de 1997, quando da promulgação do Decreto ㄲo 2.208/1997, que regulamentaram a política de EPT sob gestão dos estados.

A eleição desses dois momentos históricos se justifica, em parte, pelo fato de que, em anos anteriores, a EPT era regida pelo Decreto № 2.208/1997, que subsidiava a oferta de cursos subsequentes, e delimitava uma formação geral dissociada da Educação Profissional. Esse decreto produziu o desaparelhamento dos estados no tocante à oferta de EPT e contribuiu para o fechamento de unidades de ensino.

O Decreto $n^{0}$ 5.154/2004, ao contrário, regulamentou aquela relação, ou seja, estabeleceu a Educação Profissional integrada ao Ensino Médio modalidade de ensino que possibilita a apropriação de conhecimentos e experiências que favorecem a inserção do estudante no mundo do trabalho, bem 
como o prosseguimento de estudos (BRASIL, 2005). Essa oferta é destinada a quem concluiu o Ensino Fundamental, sendo o curso planejado de modo a conduzir o aluno à habilitação profissional técnica de nível médio, na mesma instituição de ensino, contando com matrícula única para cada aluno (BRASIL, 2004).

É válido ressaltar que os demais tipos de ofertas - concomitante (concedida somente a quem já tenha concluído o Ensino Fundamental ou esteja cursando o Ensino Médio, na qual se prevê a complementariedade de estudos, de cunho profissional em outro turno/instituição, assim como a oferta subsequente, oferecida a quem concluiu o Ensino Médio - são mantidas e convivem em harmonia com a oferta integrada.

Com base nessa relação entre Ensino Médio e formação profissional, e considerando as demandas de estados e municípios, bem como uma política de expansão da EPT, o governo federal, por meio do Decreto $n^{\circ}$ 6.302/2007, instituiu - Programa Brasil Profissionalizado. Nesse caso, o programa tinha como prioridade a oferta integrada, e foi a partir dessa premissa que os estados firmaram convênios com o Ministério da Educação. Desta forma, é pertinente propor um estudo que permita avaliar a forma de gestão dos estados, considerando a finalidade precípua daquele programa, no que se refere à oferta de cursos técnicos nos dois contextos (Bahia e Acre).

Essa avaliação está pautada em algumas variáveis que permitem conhecer os elementos que impactam no tipo de oferta e no ano da oferta de cursos técnicos, levando em conta a categoria do modelo de gestão, tomando como objeto inicial o termo "gestão da educação".

Conforme previsto na LDBEN o 9.394/96, a gestão da educação se desenvolve por meio da organização dos sistemas de ensino federal, estadual e municipal, com competências especificas da União, dos Estados e dos Municípios. Nesse sentido, é possível conceituar "gestão da educação" como competência do Estado que abarca uma amplitude de ações e iniciativas para implementação da política de educação básica. Para tanto, demanda disponibilidade financeira, recursos humanos e outras condições materiais e imateriais. 
Essa disponibilidade financeira impacta diretamente na gestão escolar. E sobre essa questão, Martins (2008, p. 3) afirma que, dentre os diferentes estudos sobre o processo de organização, gestão, constituição e exercício da autonomia escolar, o elemento comum é a distância entre as diretrizes governamentais e a efetiva operacionalização nas escolas. Isso se dá em função da ausência de sustentabilidade financeira, administrativa e pedagógica por parte das esferas executivas diante da ampliação das demandas que recaem sobre as escolas, professores e equipes de direção. Para isso, a autora sugere a realização de pesquisas que avaliem políticas de educação, a partir de outros enfoques, e permitam analisar, dentre outros aspectos, programas e projetos de governo quanto à operacionalização dos mesmos nas redes (MARTINS, 2008, p. 3).

Deste modo, esta reflexão teve por base a oferta de cursos técnicos integrado, concomitante e subsequente - dos estados da Bahia e do Acre, em consonância com os arranjos produtivos locais (APL's), conforme preconiza o art. 1ํ do Decreto ํo 6.302/2007. Esses arranjos podem ser conceituados como um conjunto de fatores econômicos, políticos e sociais localizados em um mesmo território, desenvolvendo atividades econômicas correlatas e que apresentem vínculos de produção, interação, cooperação e aprendizagem (REDESIST, 2003, p. 3).

\section{Um breve roteiro para construir as evidências}

Partindo da indagação sobre como os estados da Bahia e do Acre administram a política de Educação Profissional, foi possível levantar dados em documentos oficiais, dos respectivos governos; e quanto ao tipo de oferta de cursos técnicos patrocinados pelo Brasil Profissionalizado, utilizou-se a base de dados do Sistema de Informações da Educação Profissional e Tecnológica SISTEC, e o Sistema Integrado de Monitoramento Execução e Controle - SIMEC (indicadores públicos), ambos mantidos na página da internet do Ministério da Educação. Portanto, esse levantamento consistiu na identificação de algumas variáveis como tipo e ano da oferta dos cursos técnicos, elementos analisados com base em fontes oficiais dos estados escolhidos e do governo federal. Portanto, contemplou um processo descritivo e analítico. 
A eleição dos dois contextos (Bahia e Acre) se justifica, em parte, por representarem estados com processos históricos diferenciados em relação à oferta de Educação Profissional - um (Bahia) com evidência de longa trajetória de oferta desse ensino, inclusive por ser um dos primeiros a organizar-se como estado, enquanto que o outro (Acre) evidencia uma trajetória mais recente na implementação dessa oferta de ensino. Além disso, pertencem a regiões geográficas distintas - Nordeste e Norte do país, respectivamente.

\section{Algumas indicações reveladas}

A análise dos estados em questão evidenciou resultados diferenciados, sobretudo no tocante ao modo de gestão. Constatou-se a presença de organismos gestores diferenciados na implementação da política de Educação Profissional. Para efeitos de comparação, foram identificados os últimos Relatórios de Gestão de 2013 e 2014 da SETEC/MEC, enviados aos órgãos de controle (CGU/TCU). Neles se verificou que o Programa Brasil Profissionalizado teria investido em todos os 27 estados e envolveu a ampliação, construção ou reforma de escolas (BRASIL, 2013, p. 35). As matrículas com o Brasil Profissionalizado totalizaram 70.355 , em 2013, ante uma previsão de 172.321, sendo que $45 \%$ estavam concentradas nas regiões Norte e Nordeste, o que justifica a escolha dos estados a seguir apresentados. Os dados anteriores são de difícil compilação, uma vez que, em termos operacionais, os dados do Brasil Profissionalizado aparecem como uma das ações do PRONATEC. Em 2014, por exemplo, quando o programa atingiu seu ápice em todas as suas ações, são apresentados dados de que o programa contemplou 86 mil matriculas (BRASIL, 2014, p. 155).

Os dados do SIMEC, por exemplo, onde se monitora a execução dos convênios firmados, a partir da vigência do PRONATEC - entre 2012 e 2016 -, destaca que mais de três mil obras foram contratadas nos estados entre construção, ampliação e reforma de escolas. De longe, o estado da Bahia concentrou o maior volume destas ações com 357 intervenções, entre novas escolas, reformas e ampliações de unidades escolares. 


\section{O caso do Acre}

O Acre é um dos mais recentes estados da federação e enfrenta, entre outros aspectos, o desafio de implementar a política de Educação Profissional em condições bastante diferenciadas de estados do Sul do País a começar pela sua localização em plena floresta amazônica. Foi criado a partir da Lei ㄲo 4.070, de 15 de junho de 1962, como resultado de vários embates - seja no território nacional ou com o governo boliviano, uma vez que sua área foi comprada da Bolívia no início do século XX. Sua população atual é de 709.101 habitantes (IBGE, 2014).

As ações de Educação Profissional no Acre foram desenvolvidas por meio do Instituto Dom Moacyr (criado pela Lei ํㅜ 1.695/2005), como autarquia, com autonomia financeira, administrativa e pedagógica (ACRE, 2013). Esse instituto tem como responsabilidade a coordenação da política pública de Educação Profissional do estado. Para tanto, oferta cursos por meio dos Centros de Educação Profissional e Tecnológica - CEPT's.

A partir de revisão de estudos já realizados, foi possível identificar que o estado do Acre possui uma diversidade de arranjos produtivos locais: agricultura, avicultura, castanha, cerâmica, construção civil, farinha, madeira, movelaria, pecuária de leite e produtos florestais não madeireiros (REDESIST, 2010, p. 42). Com base nessa abrangência, é possível constatar que a oferta de cursos de Educação Profissional, proposta pelo estado, está aquém dessa realidade, já que as áreas de abrangência sugeridas pela REDESIST apresentam um leque bem mais amplo. Diferentemente, os dados levantados apontam que o estado concentra ofertas de cursos na área de serviços e comércio. Essa opção está relacionada à ideia de serem cursos de baixo custo e de fácil execução.

Desta forma, é possível constatar que a proposição de cursos, pelo estado, estava aquém das demandas do público. Quanto à oferta de cursos concomitantes, esses passaram a serem ofertados posteriormente, desde 2011, pelo Programa Nacional de Acesso ao Ensino Técnico e Emprego - PRONATEC. Essa oferta se subdivide em dois tipos de ofertas: concomitante interno e concomitante externo.

A oferta de tipo interno refere-se aos cursos em que o estudante frequenta o Ensino Médio em uma escola, em um turno, e realiza a formação profissional, 
no turno oposto, na mesma escola. Já o concomitante externo, diz respeito à oferta em que o estudante frequenta o Ensino Médio em uma escola regular e o curso técnico no Instituto Dom Moacyr (Acre, 2013).

Essa possibilidade de articulação com dois polos formativos - escola e IDM - fortalece a concentração de especificidades tecnológicas, em determinados centros. Isso viabiliza o fortalecimento de áreas tecnológicas, por meio da otimização de recursos financeiros e humanos, tendo em vista que favorece a concentração de profissionais/docentes em um mesmo espaço de atuação.

Alvarez (2013) destaca o protagonismo do IDM na gestão da Educação Profissional do estado do Acre. A partir da sua criação, todas as ações que se relacionavam com Educação Profissional no estado foram por ele assumidas, antecipando, de alguma forma, o que se pretendeu introduzir, desde 2011, no plano federal, com o PRONATEC. Em particular, a autora chama a atenção para o caráter inovador no planejamento das ações, uma vez que contava com grande articulação junto à sociedade. E seus cursos eram precedidos por amplos processos de consultas e de pesquisas, como a realizada em 2008, quando interrogou, numa amostra estratificada, os jovens dos municípios acreanos com a pergunta: o que você quer para o seu futuro? (ALVAREZ, op. cit., p. 82).

\section{O caso da Bahia}

O estado da Bahia foi um dos primeiros estados organizados do território brasileiro, contando hoje com população de 15,2 milhões de habitantes. Nesse sentido, apesar da larga trajetória na área de educação e sobretudo de Educação Profissional, também enfrenta um desafio em gerar oportunidades para um número populacional tão expressivo.

Revisando a história, pode-se constatar que esse estado foi um dos primeiros do país a criar o Liceu de Artes e Ofícios, que integrou as primeiras escolas criadas em 1909 pelo presidente Nilo Peçanha. Com o processo de expansão da Rede Federal, foram criados dois Institutos Federais (o Baiano e o da Bahia), há ainda importantes unidades do Sistema S, em particular, o SENAI Cimatec, que é referência na área de formação tecnológica. Entretanto, no ano posterior a publicação do Decreto no 5.154/2004, o governo da Bahia dispunha de 
uma oferta tímida de Educação Profissional, justificada, em parte, pela baixa capacidade operativa, tendo em vista a forma de gestão dessa modalidade de ensino, que estava alocada em uma coordenação da Secretaria de Educação e que tivera uma expansão de unidades na vigência do PROEP, durante os governos carlistas. Até o início de 2007, a gestão dessa modalidade de ensino esteve sob a responsabilidade da Coordenação de Educação Profissional, vinculada à Superintendência de Educação Básica, da Secretaria de Educação do Governo do Estado. Nesse período, o governo possuía uma rede de educação composta por apenas 37 unidades de ensino, chegando a ofertar, no início de 2007, cerca de 5.890 vagas de Ensino Médio integrado à Educação Profissional, distribuídas em 25 unidades de ensino, em todo o estado.

O total de vagas ofertadas de EPT, no final de 2006, era de 9.130 vagas, distribuídas em 37 unidades de ensino - 21 unidades ofertavam somente o integrado, 8 ofertavam somente 0 subsequente, 4 ofertavam somente 0 concomitante, 2 ofertavam integrado e subsequente e 2 ofertavam integrado, subsequente e concomitante (GOVERNO DO ESTADO DA BAHIA, 2007). Nessa época, o estado da Bahia foi um dos poucos a ofertar o Ensino Médio (modalidade EJA) com a Educação Profissional. Ao final de 2007, o estado já dispunha de 41 centros com oferta integrada, 28 com oferta concomitante e 36 com oferta subsequente (sem mencionar a variedade de ofertas por um mesmo centro).

Vale ressaltar que, nesse contexto, a criação do Fórum de Educação Profissional do Estado da Bahia, ocorrida no final de 2006, teve a intenção de fortalecer a política de EPT na região.

Em função da necessidade de expansão dessa rede, por ter sido considerada prioridade para o governo da época, aquela coordenação foi transformada em superintendência. Desde o ano de 2007, a oferta de Educação Profissional do governo da Bahia passou a ser gerida pela Superintendência de Educação Profissional (SUPROF), vinculada à Secretaria de Educação do Governo do Estado. O dinamismo desse novo ente foi favorecido pela presença do professor Antonio Almerico Biondi Lima, que havia ocupado o Departamento de Qualificação Profissional na Secretaria de Políticas Públicas de Emprego do Ministério do Trabalho e Emprego, no início da gestão do governo Lula, quando o 
ministério era ocupado por Jaques Wagner, que depois veio a ser o governador do estado por dois mandatos. Foi nesse período que ocorreu a reformulação do PLANFOR, transformado em Plano Nacional de Qualificação Profissional (PNQ). O PNQ disciplinou o formato dos cursos e, principalmente, a carga horária dos mesmos e a criação de modalidades outras, como os Planos Setoriais e Planos Territoriais de Qualificação Profissional, respectivamente, Planos Territoriais de Qualificação (PlanTeQs), Projetos Especiais de Qualificação (ProEsQs) e Planos Setoriais de Qualificação (PlanSeQs). Muito desta engenharia desenvolvida pelo PNQ foi utilizada pela recém-criada Superintendência, que incorporou ainda um acervo de informações, baseado em levantamentos e pesquisas, e iniciou um amplo processo de capacitação do quadro técnico, com o apoio das universidades estaduais baianas (CASTIONI, 2013).

Com essa nova estrutura organizacional, a rede de EPT chegou a alcançar 33 centros territoriais de Educação Profissional, 38 centros de Educação Profissional e 92 escolas de Ensino Médio que também oferecem essa modalidade de ensino (GOVERNO DO ESTADO DA BAHIA, 2018). As vagas estão distribuídas em diferentes tipos de ofertas: integrada, subsequente e concomitante.

Desta forma, a Rede Estadual de Educação Profissional e Tecnológica da Bahia objetivou consolidar e ampliar a oferta de Educação Profissional no estado, em consonância com o desenvolvimento socioeconômico e ambiental dos territórios baianos. Assim, buscou oportunizar uma formação que promova uma maior participação dos seus egressos na vida social e no mundo do trabalho dessa região. A respeito da articulação dos cursos com os arranjos produtivos locais, é fato que no ano em questão as unidades de ensino priorizavam cursos da área de serviços, comércio e agropecuária. Os dois primeiros foram eleitos mais em função do baixo custo e facilidade de contratação docente; enquanto que o terceiro guarda uma relação direta com a vocação econômica dos municípios onde estão instaladas as unidades de EPT. Em pouco tempo, a rede baiana transformou-se na segunda maior rede do País, suplantada apenas pelo Centro Paula Sousa, do estado de São Paulo.

Considerando as ofertas de Educação Profissional dos dois estados no período em questão, é possível inferir que a política de Ensino Médio integrado 
representou uma oferta tímida, haja vista a prerrogativa das normativas legais Decreto no 5.154/2004 e Decreto no 6.302/2007. Entretanto, observa-se que no estado da Bahia houve rapidamente uma ampliação significativa.

Tabela 1 - Número de estabelecimentos e suas respectivas ofertas de cursos técnicos, por ano

\begin{tabular}{|c|c|c|c|c|c|c|}
\hline \multirow{3}{*}{ Estados } & \multicolumn{6}{|c|}{$\begin{array}{l}\text { Número de estabelecimentos de acordo com o tipo de oferta de cursos } \\
\text { técnicos / ano }\end{array}$} \\
\hline & \multicolumn{3}{|c|}{2005} & \multicolumn{3}{|c|}{2008} \\
\hline & Integrada & Concomitante & Subsequente & Integrada & Concomitante & Subsequente \\
\hline ACRE & - & - & 3 & - & - & 3 \\
\hline BAHIA & 21 & 4 & 8 & 41 & 28 & 36 \\
\hline
\end{tabular}

Fonte: elaboração própria com base em dados de Viana Maya (2015) e SISTEC (2008).

\section{O Brasil Profissionalizado e o PRONATEC}

Com a criação do PRONATEC, em 2011, que passou a atuar como "guarda-chuva" dos vários programas e ofertas de EPT, o Brasil Profissionalizado foi subsumido, tendo em vista o objetivo de fomentar a ampliação da oferta de Educação Profissional em escala nacional.

Posteriormente, a partir de 2015, com a crise fiscal e o processo de impeachment, em 2016, que levou ao afastamento da presidenta Dilma Vana Rousseff, o PRONATEC veio perdendo gradativamente a importância que teve, particularmente em 2013 e 2014, quando alcançou seu auge. Nesse período, o Ministério da Educação informou ter alcançado 8 milhões de pessoas e, segundo cálculos deste autor, teria transferido $R \$ 10$ bilhões, o dobro do valor que foi investido para a expansão da Rede Federal.

Indicadores mais recentes, contidos nos Relatórios de Gestão da SETEC, demonstram que o Brasil Profissionalizado estabilizou sua oferta de matrículas na faixa dos 90 mil, o que indica que muito provavelmente tenha alcançado seu ponto de saturação em termos de oferta de vagas. Considerando que a tendência do MEC hoje seja diferente do período em que foi concebido o Brasil Profissionalizado, é de se esperar que a oferta do Ensino Médio integrado perca 
terreno para outras ofertas estimuladas pelos novos formatos de Ensino Médio previstos pela atual legislação.

Tabela 2 - Indicadores PRONATEC

\begin{tabular}{c|c|c}
\hline \multirow{2}{*}{ Iniciativa } & \multicolumn{2}{|c}{ Indicadores PRONATEC } \\
& \multicolumn{2}{|c}{ Matrículas } \\
\hline Acordo de Gratuidade & 123.419 & $\mathbf{2 0 1 7}$ \\
\cline { 2 - 3 } & 99.935 & 94.503 \\
\hline Brasil Profissionalizado & 86.210 & 96.317 \\
\hline Bolsa-Formação (Técnico e FIC) & 51.688 & 35.999 \\
\hline E-TEC & - & 65.637 \\
\hline MédioTEC & - & 645.927 \\
\hline
\end{tabular}

Fonte: SETEC. Extraído de: Avanços e Resultados da Gestão da SETEC, 2016 2017 - Relatório de Gestão Interno. Brasília: SETEC, 2015.

\section{Considerações finais}

A análise da prática de gestão dos dois estados, no que diz respeito ao Programa Brasil Profissionalizado, evidencia dinâmicas sociais diferenciadas na forma de implementar a oferta de EPT, considerando as diretrizes desse programa.

Em relação à Bahia, o modelo de gestão foi resultante de um processo sistemático de criação de órgão colegiado (Fórum de EPT) que subsidiou a consolidação da EPT enquanto política do estado, e posteriormente, com a criação de uma superintendência específica de EPT. Esse processo corroborou para uma política de EPT, de âmbito estadual, com diversidade de ofertas subsequente, concomitante e integrada. Aqui cabe destacar a iniciativa da oferta do PROEJA. No entanto, tal processo ainda se ressente de uma relação mais direta com os arranjos produtivos locais.

Quanto ao Acre, a criação do Instituto Dom Moacyr representou um avanço para o estado, tendo em vista a autonomia desse órgão no que diz respeito à gestão do recurso público, com possibilidade de contratação direta de professores, assim como à possibilidade de concentração de ofertas de EPT, 
vinculadas a determinadas áreas tecnológicas. No entanto, nesse estado também se nota a falta de uma articulação da EPT com os arranjos produtivos locais.

A análise desses casos, em particular, aponta para a criação de uma nova solução para a governança da Educação Profissional. A esse respeito, é válido ressaltar a experiência de outros países tanto em relação à gestão da EPT quanto à participação de outros segmentos (sindicatos, conselhos regionais profissionais, empresariado, etc.). Isso sugere pensar em mecanismos de aproximação do poder público com esses segmentos, no trato dessa política - o fórum criado pelo governo da Bahia, evidencia, em parte o direcionamento para esse caminho. Nesse caso, é pertinente apontar a necessidade de maior articulação entre as ofertas do Programa Brasil Profissionalizado com a oferta do Sistema S, inclusive para suprir as demandas de escolas públicas no tocante à nova forma de organização do novo Ensino Médio.

Em boa medida, a articulação do Fórum dos Gestores Estaduais de Educação Profissional propiciou a descoberta de novas iniciativas de organização e gestão da Educação Profissional. A criação de unidades com autonomia de gestão baseou-se na experiência da própria rede Paula Sousa, em São Paulo; nos estados do Rio Grande do Sul, com a Superintendência da Educação Profissional (SUEPRO); e no estado de Alagoas, com o Instituto de Educação Profissional (INEPRO), no qual o estado do Acre se inspirou para organizar o Instituto Dom Moacyr.

Aqui cabe destacar a necessidade de implementação de estudos para o desenvolvimento de metodologias de monitoramento e acompanhamento, avaliação e supervisão da EPT (a qual, inclusive, perpassa pela otimização da plataforma do SISTEC). Também é necessária a estruturação e redefinição da oferta de PROEJA, na expectativa de atender um público maior, visando garantir maior possibilidade de acesso e equidade para jovens e adultos que buscam na educação caminhos para inserção laboral e melhoria de sua qualidade de vida, sobretudo pelo fato de se constituir em uma oferta a mais para um público cada vez mais jovem que migra para classes de adultos. E, acima de tudo, é preciso proporcionar Educação Profissional de qualidade com oferta regular pelos estados brasileiros que concentram o maior volume de matrículas de Ensino Médio no Brasil. 


\section{Referências}

ACRE. Governo do Estado. Instituto de Desenvolvimento da Educação Profissional Dom Moacyr. Disponível em: <http://www.idep.ac.gov.br>. Acesso em: 20 fev. 2018.

ALVAREZ, Carmem Paola Torres. Governança da Educação Profissional e Tecnológica: uma análise do contexto da Amazônia ocidental. 2014. 140f. Dissertação (Mestrado em Educação) - UnB. Brasília.

BRASIL. Lei $n^{0} 13.415$, de 16 de fevereiro de 2017. Institui a Política de Fomento à Implementação de Escolas de Ensino Médio em Tempo Integral. Brasília: Diário Oficial da União. <http://www.planalto.gov.br/ccivil_03/_ato20152018/2017/lei/l13415.htm>. Acesso em: 20 fev. 2018.

. Lei $n^{0} 12.513$, de 26 de outubro de 2011. Institui o Programa Nacional de Acesso ao Ensino Técnico e Emprego (Pronatec). Brasília: Diário Oficial da União. Disponível em: <http://www.planalto.gov.br/ccivil_03/_ato2011-2014/2011/ lei/12513.htm>. Acesso em: 20 fev. 2018.

. Lei no 4.070, de 15 de junho de 1962. Disponível em: <htpp://www. planalto.gov.br/ccivil_03/leis/1950-1969/L4070.htm>. Acesso em: 20 fev. 2018.

. Decreto oㅜ 6.302, de 12 de dezembro de 2007. Brasília: Diário Oficial da União. Institui o Programa Brasil Profissionalizado. Disponível em: <http://www.planalto.gov.br/ccivil_03/_Ato2007-2010/2007/Decreto/D6302.htm>. Acesso em: 20 fev. 2018.

. Decreto $\mathrm{n}^{0} 5.154$ de 23 de julho de 2004. Regulamenta o $\S 2^{\circ}$ do art. 36 e os arts. 39 a 41 da Lei ํo 9.394, de 20 de dezembro de 1996, que estabelece as diretrizes e bases da educação nacional, e dá outras providências. Brasília: Diário Oficial da União. Disponível em: <http://www.planalto.gov.br/ccivil_03/_Ato20042006/2004/Decreto/D5154.htm>. Acesso em: 20 fev. 2018.

Ministério da Educação. O Plano de Desenvolvimento da Educação. Razões, Princípios e Programas. Brasília-DF, 2007. Disponível em: <http://www. dominiopublico.gov.br/download/texto/me004370.pdf>. Acesso em: 20 fev.2018. . Avanços e Resultados da Gestão da SETEC, 2016 - 2017 - Relatório de Gestão Interno. Brasília: SETEC, 2015.

Ministério da Educação, Secretaria de Educação Profissional e Tecnológica. Prestação de Contas Ordinária Anual. Relatório de Gestão Consolidado do Exercício 2014. Brasília: MEC/SETEC, 2015. Disponível em: <htppp://www.encurtador.com.br/gqIKL>. Acesso em: 20 fev. 2018.

Ministério da Educação, Secretaria de Educação Profissional e Tecnológica. Relatório de Gestão do Exercício de 2013. Brasília: MEC/SETEC, 2014. Disponível em: <htppp://www.encurtador.com.br/puzlZ>. Acesso em: 20 fev. 2018. 
CASTIONI, Remi. Educação no Mundo do Trabalho: qualificação e competência. São Paulo: Francis; Brasília: Verbena, 2010.

Planos, Projeto e Programas da Educação Profissional: Agora é a vez do PRONATEC. Revista Sociais e Humanas, Santa Maria, v. 26, n. 1, p. 25-24, jan./abr. 2013.

FASOLO, Camila Porto; CASTIONI, Remi. Educação Profissional no PNE 20142024: contexto de aprovação e monitoramento da meta 11. Linhas Críticas, v. 22, p. 577-597, 2017.

GOVERNO DO ESTADO DA BAHIA. Secretaria de Estado de Educação. Superintendência de Educação Profissional. Disponível em: <http://escolas. educacao.ba.gov.br/ redeep>. Acesso em: 20 fev. 2018.

MARTINS, Ângela Maria; SILVA, Vandré Gomes da. Estado da Arte: Gestão, Autonomia da Escola e Órgãos Colegiados (2000/2008). Caderno de Pesquisa, jan./abr. 2011. Disponível em: <htppp://www.periódicos.capes.gov.br/portugues/ index.jsp>. Acesso em: 11 jan. 2018.

REDESIST. Rede de Pesquisa em Sistemas Produtivos e Inovativos Locais. Arranjos produtivos locais: uma nova estratégia de ação para o Sebrae. Disponível em: <htppp://www.ie.ufrj.br/redesist>. Acesso em: 20 fev. 2018.

SANTIAGO CONSULTORES. Evaluación en profundidad del Programa CHILECALIFICA: resumen Ejecutivo, 2009. Disponível em: <http://www.dipres. gob.cl/597/articles-141078_informe_final.pdf>. Acesso em: 20 fev. 2018.

VERA, Alejandro; CASTIONI, Remi. Los jóvenes en Latinoamérica. La transición escuela-trabajo como objeto de las políticas públicas. Boletim Técnico do SENAC, v. 37, p. 10-20, 2010.

VIANA, Cláudia Ferreira de Maya. Programa Brasil Profissionalizado: coordenação federativa, formulação e implementação da política nacional de expansão das redes estaduais de Educação Profissional. Perspectivas em Políticas Públicas, Belo Horizonte, v. X, n. 19, p. 129-163, jan./jun. 2017.

WEREBE, Maria Jose Garcia. 30 anos depois: grandezas e misérias do ensino no Brasil. São Paulo: Ática, 1994. (Série Educação em Ação).

Recebido em: 05 de março de 2018.

Aprovado em: 09 de maio de 2018.

Publicado em: 21 de novembro de 2018. 